\title{
Numerical Investigation of Critical Velocity in Reduced Scale Tunnel Fire with Constant Heat Release Rate
}

\author{
Ruben Mouangue, ${ }^{1}$ Philippe M. Onguene, ${ }^{1,2}$ Justin T. Zaida, ${ }^{3}$ and Henri P. F. Ekobena ${ }^{4}$ \\ ${ }^{1}$ Laboratory of Combustion and Green Technologies, Department of Energy Engineering, University Institute of Technology, \\ University of Ngaoundere, P.O. Box 455, Ngaoundere, Cameroon \\ ${ }^{2}$ Department of Electrical Engineering, Energy and Automatics, National School of Agro-Industrial Sciences, \\ University of Ngaoundere, Ngaoundere, Cameroon \\ ${ }^{3}$ Department of Physics, University of Fada, Gourma Province, Burkina Faso \\ ${ }^{4}$ Laboratory of Analysis, Simulation and Experiment (LASE), Department of Energy Engineering, University Institute of Technology, \\ University of Ngaoundere, P.O. Box 455, Ngaoundere, Cameroon \\ Correspondence should be addressed to Ruben Mouangue; r_mouangue@yahoo.fr
}

Received 6 September 2016; Revised 23 November 2016; Accepted 12 December 2016; Published 18 January 2017

Academic Editor: Kaiyuan Li

Copyright (C) 2017 Ruben Mouangue et al. This is an open access article distributed under the Creative Commons Attribution License, which permits unrestricted use, distribution, and reproduction in any medium, provided the original work is properly cited.

When a fire occurs in a tunnel in the absence of sufficient air supply, large quantities of smoke are generated, filling the vehicles and any space available around them. Hot gases and smoke produced by fire form layers flowing towards extremities of the tunnel which may interfere with person's evacuation and firefighter's intervention. This paper carries out a numerical simulation of an unexpected fire occurring in a one-way tunnel in order to investigate for the critical velocity of the ventilation airflow; this one is defined as the minimum velocity able to maintain the combustion products in the downstream side of tunnel. The computation is performed successively with two types of fuels representing a large and a small heat release rate, owing to an open source CFD code called ISIS, which is specific to fires in confined and nonconfined environments. It is indicated that, after several computations of full-scale fires of $43.10^{3}$ and $19.10^{3} \mathrm{~kJ} / \mathrm{kg}$ as heat release rate, the velocities satisfying the criterion of healthy environment in the upstream side of the tunnel are $1.34 \mathrm{~m} / \mathrm{s}$ and $1.12 \mathrm{~m} / \mathrm{s}$, respectively.

\section{Introduction}

Fires in tunnels, in underground mine roadways, and in building corridors have generally a very complex flow structure because of their geometry and the found ventilation system which can be natural or forced; that is the reason why fires occurring in these places often cause important damage in terms of human being life and material losses. The most remaining case of large-scale tunnel fire is the one of the Mont Blanc in 1999 caused by an accident of a cargo truck carrying margarine and flour. This incident has caused 39 deaths and left 30 people injured [1]. Fire occurred in the same tunnel again in 2005 where two people died and many were injured. Another fire broke out in October 2001 in the SaintGotthard tunnel, Switzerland: two cargo trucks came into collision involving 11 deaths. In the Hongjimun tunnel, Korea, there was an accident on 6 June 2003, in which a minibus and a four-wheeled vehicle clashed, leading to a fire breakout; about 40 people were seriously injured [2].

As a result of the above situations, the interest in fire safety science of tunnels has, however, increased mainly due to the increasing number of catastrophic tunnel fires and the increasing number of tunnels built. Numerous universities, research institutes, and large engineering companies have become involved in many tunnel fires studies. In order to understand the basic tunnel fire phenomena, several studies carried out by authors were focused on both reduced scale [3] and full-scale tests [4]. Generally, the most immediate threat to life in tunnel fires is not the direct exposure to fire but the smoke inhalation. In the case of ventilated tunnel, smoke and hot combustion products may form a layer near the ceiling called back layer which flows in the 


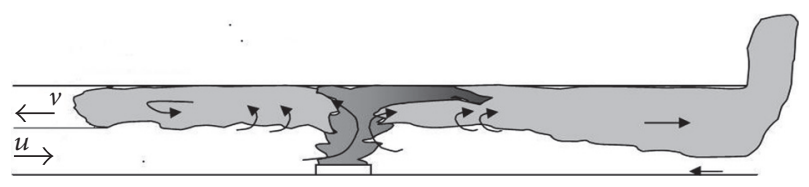

FIGURE 1: Illustration of the back-layer velocity $(v)$ opposite to the ventilation velocity $(u)$.

opposite direction of the ventilation stream. The existence of this reverse stratified layer of hot combustion products has an important bearing on fire fighting and evacuation of underground mine roadways, tunnels, and building corridors $[5,6]$. So in the event of a tunnel fire, the main concern is to maintain an evacuation path that is free of smoke and hot gases. Efficient control of smoke propagation is, therefore, one of the most important issues in designing tunnel ventilation and a full understanding of the characteristics of smoke propagation in tunnels is a necessity in order to proceed with a successful design. It seems then to be very important to devise evacuation measures and prepare for a proper smoke ventilation system inside tunnels [7-11].

The most recent technique to study behavior of tunnel fires is by using Computational Fluid Dynamics (CFD). This approach is capable of modeling the multidimensional, timedependent nature of fire in both obstructed and unobstructed tunnels of arbitrary geometry. However, the accuracy of the CFD modeling depends on the accuracy of the physical models employed in the CFD codes [12, 13]. The most important task at this stage is the validation of the computer code. The suitability of the turbulence and combustion models has remained the most important issue. Many studies have already been done about fire using CFD codes [14-18]. Concerning the behavior of smoke and gas products, authors have performed several simulations in order to know about the phenomenon of back layer and the impact of ventilation system on it. The obtained results showed that the existence and then the length of a back layer in the upstream side of the fire source are a function of ventilation velocity $[19,20]$. The critical velocity " $u_{\mathrm{cr}}$ " is just the sufficient velocity provided by the ventilation system, able to prevent formation of this reverse stratified layer. In other words, it is the minimum velocity of draught able to counter fire products velocity (Figure 1).

After a validation test elaborated by developers of the used CFD code in order to demonstrate its accuracy to represent reality by comparing experiment and simulation, this paper presents a numerical investigations carried out on a small scale tunnel model to study the spread of smoke and hot gases during tunnel fire. Then, from which velocity of the longitudinal ventilation systems will the back layer be deleted? This question will be answered by assuming the heat release rate of fire constant in the small scale tunnel. Results will therefore be extrapolated in full-scale dimensions.

The contribution of the present paper is firstly to put numerically in evidence the complexity of fire in particular geometries, especially in tunnels. Secondly, this paper set a way for ventilation system design by introducing a manner to investigate critical velocity in a given fire incident.
TABLE 1: Constants of standard $k-\varepsilon$ model.

\begin{tabular}{cccccccccc}
\hline$C_{R}$ & $C_{\mu}$ & $C_{1 \varepsilon}$ & $C_{2 \varepsilon}$ & $C_{3 \varepsilon}$ & $\sigma_{k}$ & $\sigma_{\varepsilon}$ & $\sigma_{z}$ & $\sigma_{Y}$ & $\sigma_{h}$ \\
\hline 4 & 0.09 & 1.44 & 1.92 & 1.44 & 1.0 & 1.3 & 0.7 & 0.7 & 0.7 \\
\hline
\end{tabular}

\section{Materials and Methods}

2.1. CFD Code. The basic CFD framework used for the present study is ISIS. This open source code covers a wide range of applications including laminar or turbulent, reactive, incompressible, and low Mach flows governed by NavierStokes equations such as continuity and momentum equations coupled with equations of energy and species concentrations [21]. Like other CFD codes (Figure 2), ISIS is based on the scientific computing development platform PELICANS, which offers a library of software components. ISIS is entirely parallelized via this platform, for both assembly and solution of discrete systems. In addition, it is possible to solve problem using exterior libraries, available as open source software. For the present study, the code Gmsh has been used for meshes building and the code Paraview has been used to visualize the solution of the problem. All those codes are implemented in the Linux Operated System.

2.2. Numerical Model. CFD simulation is now a practical tool in fire engineering for simulating buoyancy-induced flows $[22,23]$. The computational study can be used to analyze fire related problems, such as temperature, velocity, and concentration distribution. The fire simulated for safety (ISIS, in French: Incendie Simulé pour la Sureté) is being developed to study fire behavior in confined and opened buildings. It consists of solving flow equations numerically after discretization of physical equations by finite volumes and finite elements methods; this is based on the low Mach formulation. The physical equations include Navier-Stokes equations for flow analysis, energy conservation equations for temperature distribution, and other scalar equations for smoke and particulates transport.

Turbulence methods commonly used in CFD are based on the Reynolds Averaging Navier-Stokes (RANS) equation method, Large Eddy Simulation (LES), and Direct Numerical Simulation (DNS). In this study, the RANS method is used, more precisely, the standard $k-\varepsilon$ model for turbulence. The two-variable $z-Y_{F}$ approach is used for turbulent combustion and for the radiant heat transfer; the $P-1$ model is used. The togetherness of these conservations equations is presented below. For convenience, the overline and tilde turbulent symbols are omitted [21]. Table 1 gives the constants of standard $k-\varepsilon$ model:

(i) Equation of mass:

$$
\frac{\partial \rho}{\partial t}+\nabla \cdot(\rho v)=0
$$




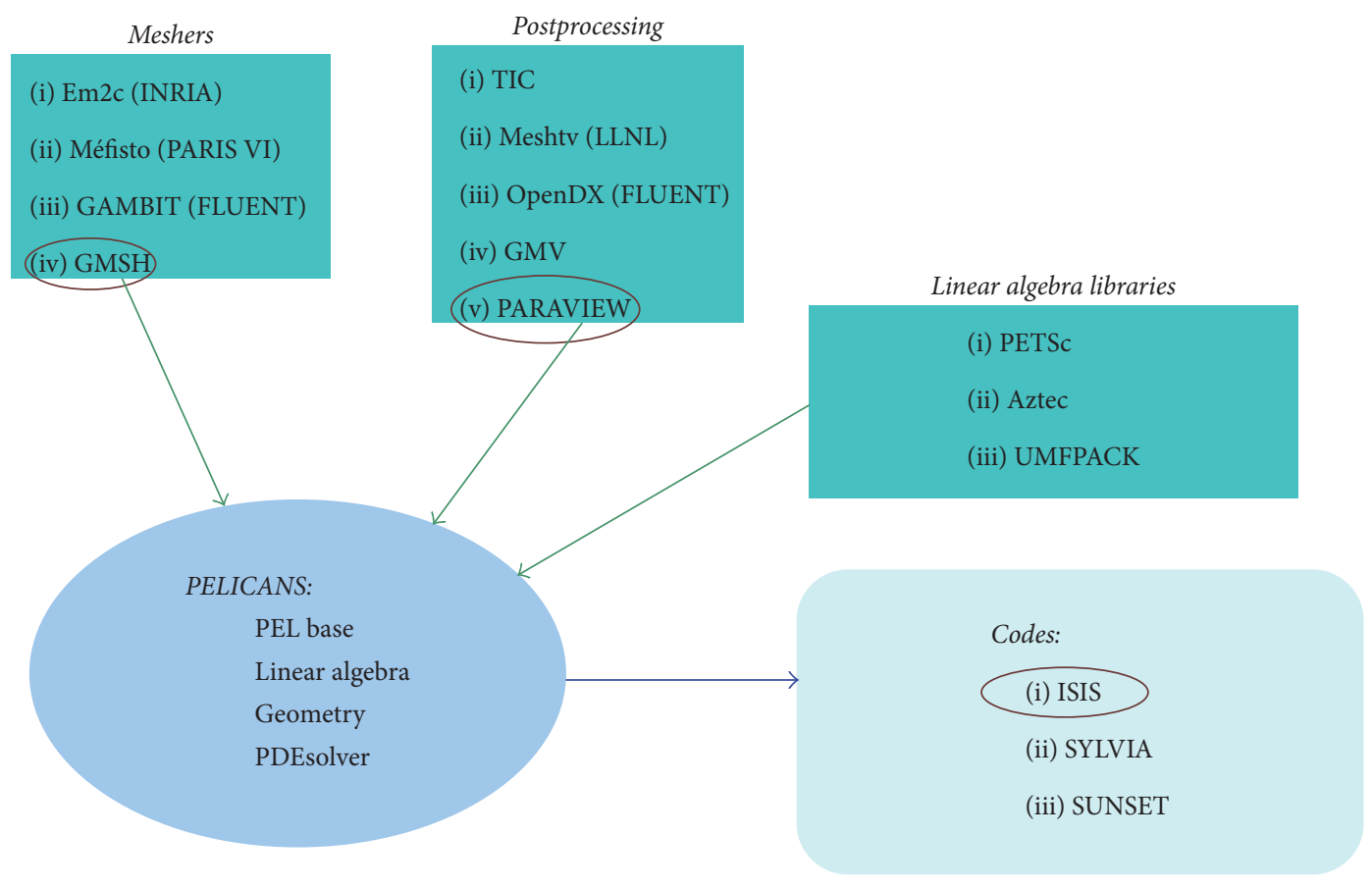

FIGURE 2: PELICANS environment.

(ii) Equation of momentum:

$$
\begin{aligned}
\frac{\partial(\rho v)}{\partial t}+\nabla \cdot(\rho v \otimes v)= & -\nabla p^{\prime}+\nabla \cdot\left(2 \mu_{e} S\right) \\
& +\left(\rho-\rho_{0}\right) g .
\end{aligned}
$$

(iii) Equation of enthalpy:

$$
\frac{\partial(\rho h)}{\partial t}+\nabla \cdot(\rho v h)=\nabla \cdot\left(\frac{\mu_{e}}{\sigma_{h}} \nabla h\right)+k G-4 k \sigma T^{4} .
$$

(iv) Equation of radiative intensity:

$$
\nabla \cdot\left(\frac{1}{3 k} \nabla G\right)-k G+4 k \sigma T^{4}=0 .
$$

(v) Equation of mixture fraction:

$$
\frac{\partial(\rho k)}{\partial t}+\nabla \cdot(\rho v z)=\nabla \cdot\left(\frac{\mu_{e}}{\sigma_{z}} \nabla z\right)
$$

(vi) Equation of fuel mass fraction:

$$
\frac{\partial\left(\rho Y_{F}\right)}{\partial t}+\nabla \cdot\left(\rho v Y_{F}\right)=\nabla \cdot\left(\frac{\mu_{e}}{\sigma_{Y}} \nabla Y_{F}\right)+\dot{w}_{F} .
$$

(vii) Equation of turbulent kinetic energy:

$$
\begin{aligned}
\frac{\partial(\rho k)}{\partial t}+\nabla \cdot(\rho v k)= & \nabla \cdot\left[\left(\mu+\frac{\mu_{t}}{\sigma_{k}}\right)+\nabla k\right]+P_{k}+P_{k b} \\
& -\rho \varepsilon .
\end{aligned}
$$

(viii) Equation of rate of turbulent kinetic energy

$$
\begin{aligned}
\frac{\partial(\rho \varepsilon)}{\partial t}+\nabla \cdot(\rho v \varepsilon)= & \nabla \cdot\left[\left(\mu+\frac{\mu_{t}}{\sigma_{\varepsilon}}\right)+\nabla \varepsilon\right] \\
& +\frac{\varepsilon}{k}\left(C_{1 \varepsilon} P_{k}+C_{3 \varepsilon} P_{\varepsilon b}-C_{2 \varepsilon} \rho \varepsilon\right),
\end{aligned}
$$

with

$$
S=\frac{1}{2}\left(\nabla v+\nabla^{t} v\right)
$$

$$
\mu_{t}=\mu+\mu_{t}
$$$$
\mu_{t}=\rho C_{\mu} \frac{k^{2}}{\varepsilon},
$$

$$
\begin{gathered}
P_{k b}=-\frac{\mu_{t}}{\rho \sigma_{g}} g \nabla \rho, \\
\rho=\frac{P W}{R T},
\end{gathered}
$$

$$
\begin{aligned}
Q_{\mathrm{rad}} & =-\nabla \cdot q_{r}=k I-4 k \sigma T^{4}, \\
h & =c_{p}\left(T-T_{0}\right)+Y_{F} \Delta H_{c},
\end{aligned}
$$$$
P_{k}=2 \mu_{t} S: \nabla v-\frac{2}{3}\left(\mu_{t} \nabla \cdot v+\rho k\right) \nabla \cdot v,
$$

$P_{\varepsilon b}=\max \left(P_{k b}, 0\right)=P_{k b}$,

$\dot{w}_{F}=-C_{R} \rho \frac{\varepsilon}{k} \min \left(Y_{F}, \frac{Y_{o}}{s}\right)$. 


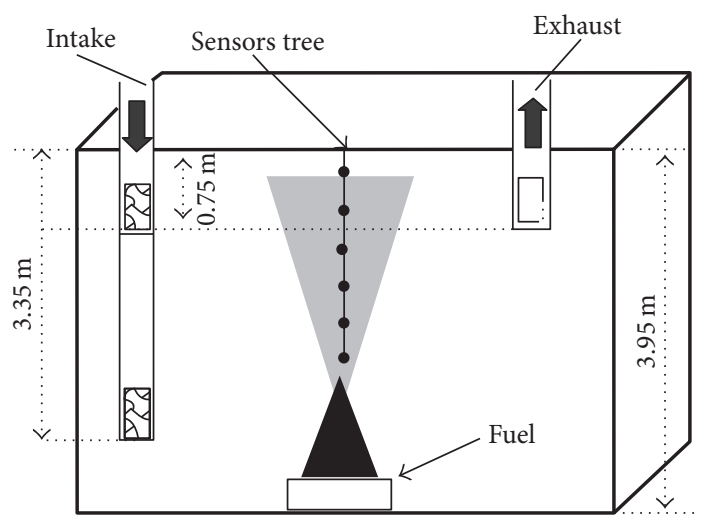

FIgURE 3: Configuration of validation test.

2.3. Froude Number's Theory. The Froude number is a dimensionless number which represents the ratio between inertia forces and gravity forces. Its formula is defined as follows, where $g$ is the force of gravity and $V$ and $D$ are characteristic values of velocity and domain length, respectively:

$$
\mathrm{Fr}=\frac{V^{2}}{g D}
$$

The Froude number modeling is often used as the scaling technique in fire situations where the Reynolds number is sufficiently large, turbulent conditions prevail, and buoyancy forces are dominant. In fact, McCaffrey and Quintiere [24] studied buoyancy driven countercurrent flows generated by a fire source and found that the general nature of the flow is not dependent on scale. This can be achieved by assuming geometric similarity and assuming dynamic similarity holds if the Froude number is maintained constant. Thus, by conserving this similarity criterion, experiment can be done in small scale (SS) and then extrapolated in full scale (FS) starting from the Froude number formula:

$$
\left(\frac{V}{H^{1 / 2}}\right)_{\mathrm{FS}}=\left(\frac{V}{H^{1 / 2}}\right)_{\mathrm{SS}},
$$

where $V$ is the velocity and $H$ the height; the Froude number criterion leads to equal corresponding temperatures between the small scale and full-scale systems. That relationship provided the following equation, with $Q$ defined as the heat generated at the fire source:

$$
\left(\frac{\dot{Q}}{H^{5 / 2}}\right)_{\mathrm{FS}}=\left(\frac{\dot{\mathrm{Q}}}{H^{5 / 2}}\right)_{\mathrm{SS}} .
$$

2.4. Configurations of Study. The validation consists in assessing the credibility of numerical simulation by determining the accuracy of the computational solution as compared to a real situation; therefore, several integral tests conducted at the IRSN Fire Test Laboratory and consisting of largescale fire scenarios in confined and mechanically ventilated compartments have enabled progress to be made in the validation process of the ISIS code. One of these experiments was the one carried out by Pretrel and coworkers [25], consisting of a fire experiment in a single compartment of dimension $5 \mathrm{~m} \times 6 \mathrm{~m} \times 4 \mathrm{~m}$. The walls were $30 \mathrm{~cm}$ thick and made of concrete and the ceiling was insulated by rock wool panels of $5 \mathrm{~cm}$ thickness. The ventilation system included intake and exhaust branches, which were located in the upper part of the compartment. The air inlet and outlet openings, located in the upper part of the compartment, have a cross section of $0.3 \times 0.6=1.18 \mathrm{~m}^{2}$ and a "west-east" flow direction (Figure 3). The renewal rate is fixed at 4.7 per hour. The fuel was hydrogenated tetrapropylene (TPH). The pool was circular with surface area $S=0.4 \mathrm{~m}^{2}$. It was raised $0.4 \mathrm{~m}$ above the floor, at the center of the fire compartment. In normal situation, the fresh air enters by the intake opening while the waste air gets out by the exhaust opening. The sensors tree has been used by authors for the measurement of temperature at different heights during fire test.

The second configuration used in this study is inspired from the work of Roh and coworkers [26]. It is a scale-model tunnel with a scaling ratio of $1 / 20^{\text {th }}$ of the full-scale tunnel of $200 \mathrm{~m}$ in length and $8 \mathrm{~m}$ in height. The reduced tunnel had an arched ceiling, a semicircular head, and a rectangular body. The height from the floor to the apex of the roof was $0.4 \mathrm{~m}$ and the width at floor level was $0.4 \mathrm{~m}$. The total length of the tunnel was around $10 \mathrm{~m}$ (Figure 4). The ventilation device is mounted at the upstream side of the tunnel in order to create a longitudinal flow. Fire will be firstly initiated inside tunnel using methane as fuel with large HRR and then methanol as fuel with small HRR. Flow rate will be changed progressively till the reaching of desired velocity. Temperature, velocity and species concentrations are measured near the ceiling by the upstream zone exactly at $z=0.3 \mathrm{~m}$ and $x=-3 \mathrm{~m}$ from the fire source.

\section{Results and Discussion}

3.1. Grid Sensitivity Analysis. Meshing often influences numerical results when grid sensitivity test is not performed. The test consists of varying number of nodes by inspecting the variation of one parameter; so, starting from coarse grid of 3,000 nodes to fine grid of 4,800 nodes, temperature above the source fire precisely at a height of $0.24 \mathrm{~m}$ near the ceiling 


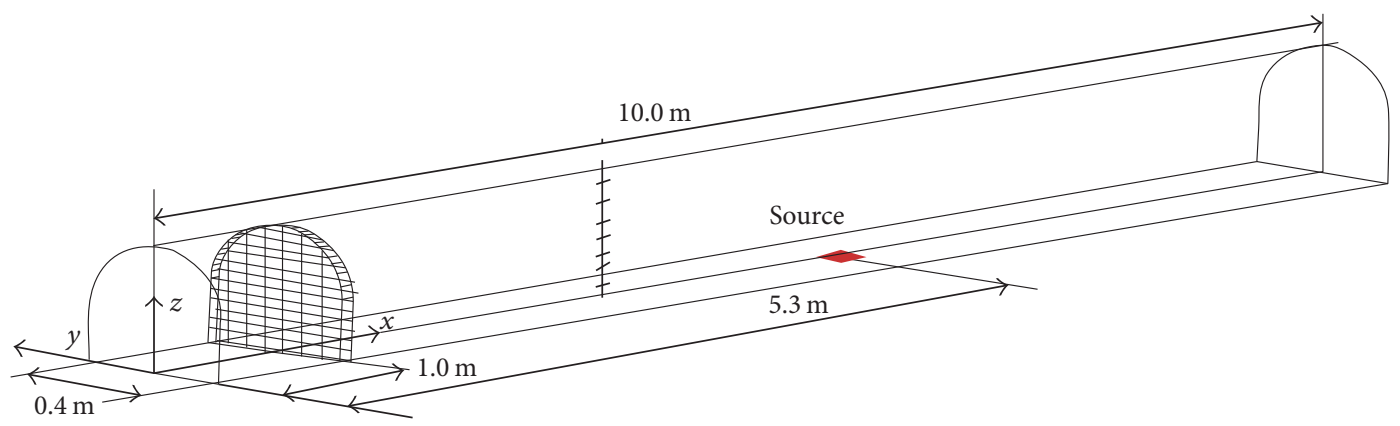

Figure 4: Configuration of reduced tunnel.

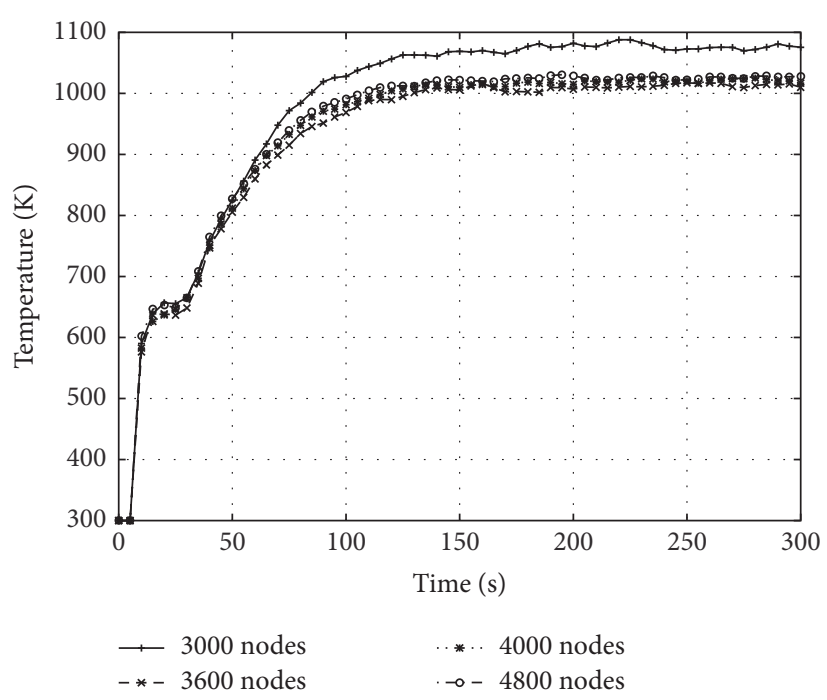

FIGURE 5: Influence of meshing on the variation of temperature.

is observed. In Figure 5, it comes out that the variation of temperature during ignition, growth, and generalization of fire is not affected by the grid after few variations of nodes. So, starting from 3,600 nodes, no significant change is notified when computation is running. That is why, in the present work, the domain of the study is subdivided in 4,000 nodes in order to minimize the computational time.

\subsection{Capacity of Code to Represent Real Fire. Concerning} the validation test, only a part of their results has been plotted over 1,500 seconds; Figures 6(a) and 6(b) represent the evolution overtime of the temperature for several heights (at points $z=0.55 \mathrm{~m}$ and $z=3.9 \mathrm{~m}$ ). In Figure 6(a), as ISIS is based on low Mach formulation, high turbulence at this point increases error while in Figure 6(b), far from the source, numerical result is slightly in conformity with experiment; but at the beginning of fire, the peak temperature is not correctly computed because of turbulence due to the full developed stage of fire in the room.

3.3. Critical Velocity Investigation. When a fire is started on the floor of a straight tunnel without a ventilation flow, a hot plume rises above the fire and involves the surrounding cold air into the plume, which, by reaching the ceiling, forms two layers of hot gases concentration flowing in opposite directions along the ceiling (Figure 7). The risk related to fires in tunnels is not therefore due to the frequency of the accident but due to the serious consequences for people and environment; then, it is of paramount importance to foresee an emergency ventilation system during the design of tunnel and select appropriate escape direction to minimize injury to people and property.

In this simulation study, it is assumed that fire is initialized; then, it grows till reaching its full developed stage with constant heat release rate. A longitudinal flow of air, provided by the ventilation system, is sent inside the tunnel in fire in order to reduce the aggressiveness of fire and maintain the upstream side of tunnel exempt of smoke and hot gases. Starting by a weak velocity in the entrance of tunnel in fire and varying it progressively, the computation is repeated until the conditions of critical velocity are reached.

3.3.1. Velocity $V_{i}=0.05 \mathrm{~m} / \mathrm{s}$. The first value of velocity injected inside the tunnel by the ventilation system is $0.05 \mathrm{~m} / \mathrm{s}$. At this velocity, many phenomena are observed in the upstream side, precisely at $3 \mathrm{~m}$ of fire source. From 0 to 10 seconds, fire is still at stage of ignition, and there is no change in measure point about the ambient parameters 


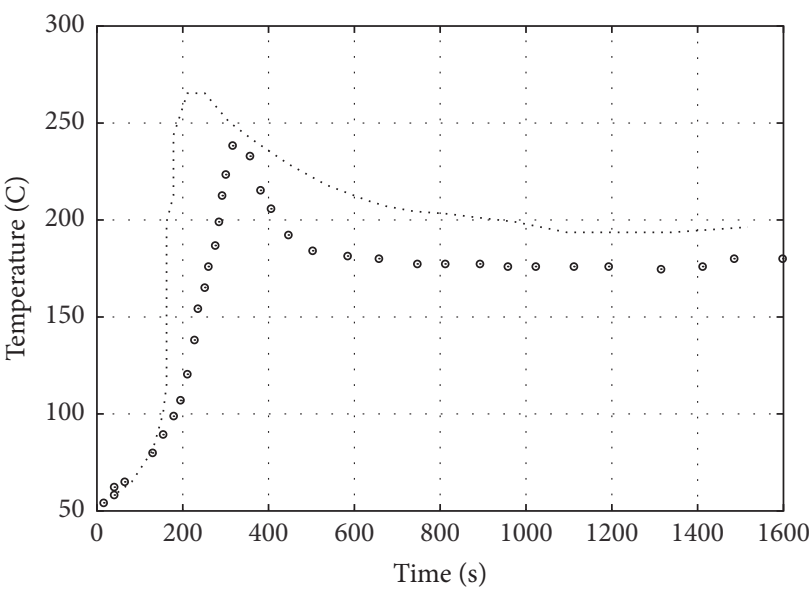

- $\operatorname{Exp}$ ISIS

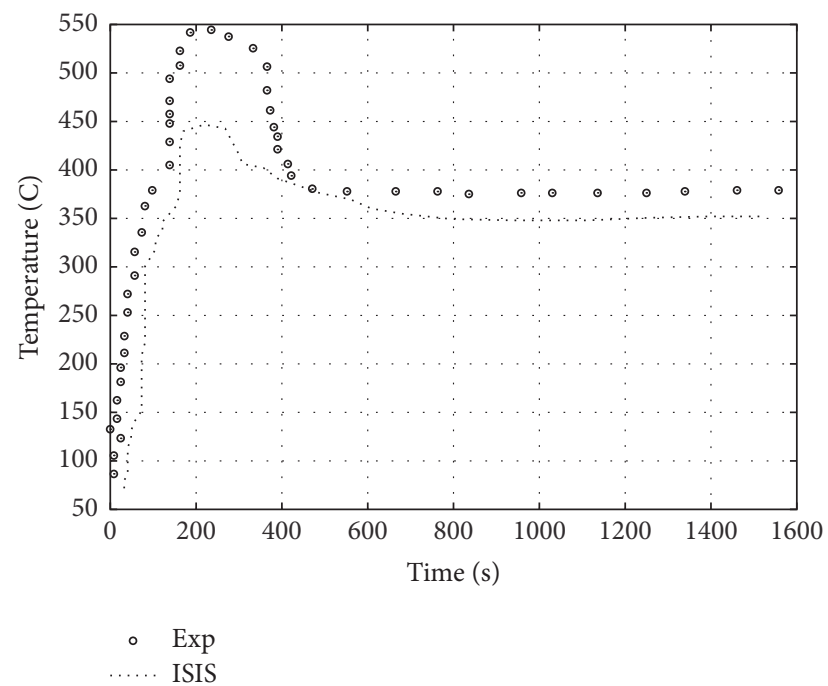

(b) $z=3.9 \mathrm{~m}$

(a) $z=0.55 \mathrm{~m}$

FIgURE 6: Temperatures at the center domain above the fire source with different height.

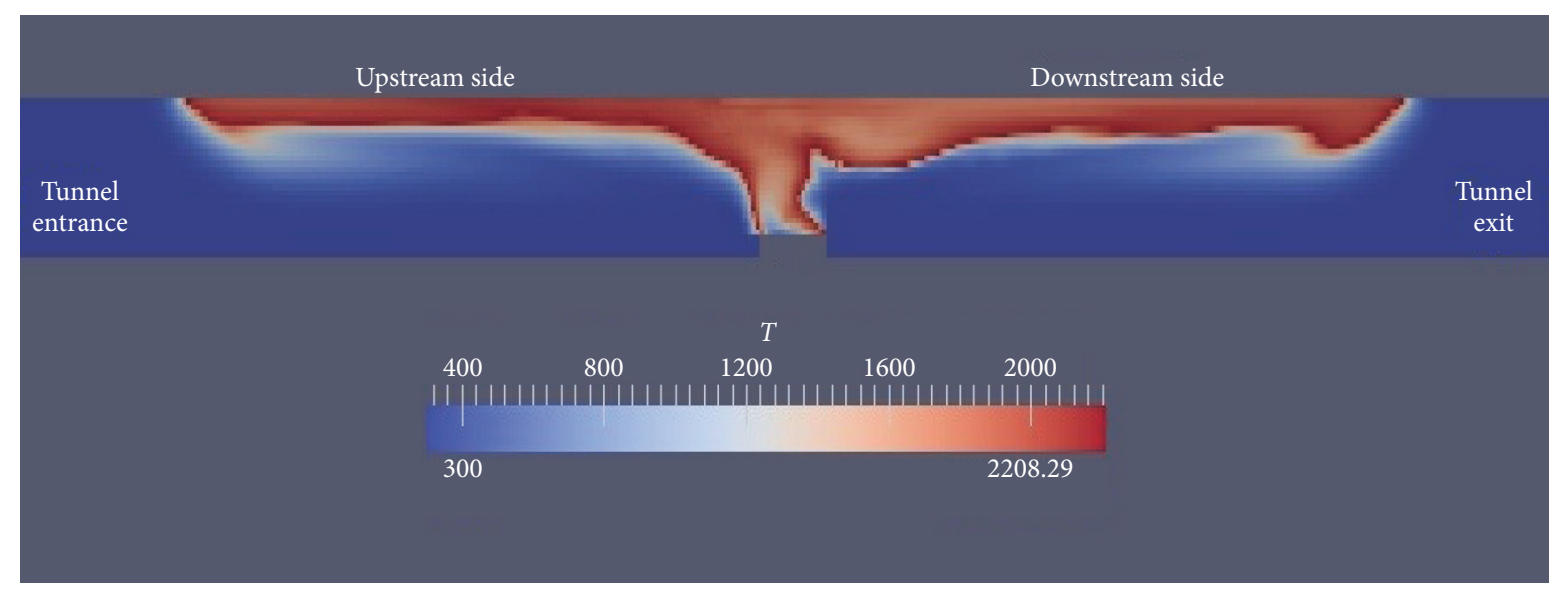

FIGURE 7: Streams of smoke and hot gases flowing in opposite directions along the ceiling.

(Figure 8); all of them are practically invariant and stay in normal conditions: the velocity is suitable to the ventilation velocity; temperature corresponds to the ambient value; the rate of oxidizer is equal to those of normal air, and there is no presence of $\mathrm{CO}_{2}$ at that stage.

From 10 to 20 seconds, after its ignition, it is stage of growth which leads directly to the full developed fire stage. The overpressure due to this generalization of fire generates a stratified layer flowing against the ventilation direction, the reason why the value of velocity falls suddenly to the negative side till reaching a peak of $-0.39 \mathrm{~m} / \mathrm{s}$ and stabilizes around $-0.15 \mathrm{~m} / \mathrm{s}$ during fire (Figure $8(\mathrm{a})$ ). So, after these transition stages, for a ventilation velocity of $V_{i}=0.05 \mathrm{~m} / \mathrm{s}$, the back layer constituted by smoke and hot gases flows with velocity $0.15 \mathrm{~m} / \mathrm{s}$. Its temperature is around $910 \mathrm{~K}$ (Figure $8(\mathrm{~b})$ ) and its contents in oxidizer and carbon dioxide are worth 0.165 and 0.052 (Figure $8(\mathrm{c})$ ), respectively. These conditions are not acceptable for prompt evacuation or help intervention; by consequence, $0.05 \mathrm{~m} / \mathrm{s}$ is insufficient.

3.3.2. Velocity $V_{i}=0.15 \mathrm{~m} / \mathrm{s}$. When computation is run using a ventilation velocity of $0.15 \mathrm{~m} / \mathrm{s}$, the velocity curve is still in the negative side (Figure 9(a)); that means that the back layer always exists and flows with a front speed of $-0.22 \mathrm{~m} / \mathrm{s}$ with a temperature of $550 \mathrm{~K}$ (Figure 9(b)). Despite their weak slide, its contents in oxidizer and carbon dioxide are worth 0.205 and 0.022 (Figure 9(c)), respectively.

3.3.3. Velocity $V_{i}=0.20 \mathrm{~m} / \mathrm{s}$. For velocity $V_{i}=0.20 \mathrm{~m} / \mathrm{s}$, after stage of transition, the velocity is around $-0.12 \mathrm{~m} / \mathrm{s}$ (Figure 10(a)); temperature is around $440 \mathrm{~K}$ (Figure 10(b)). Content in oxidizer is 0.217 and level of carbon dioxide decreases considerably and is worth 0.011 (Figure 10(c)). With 


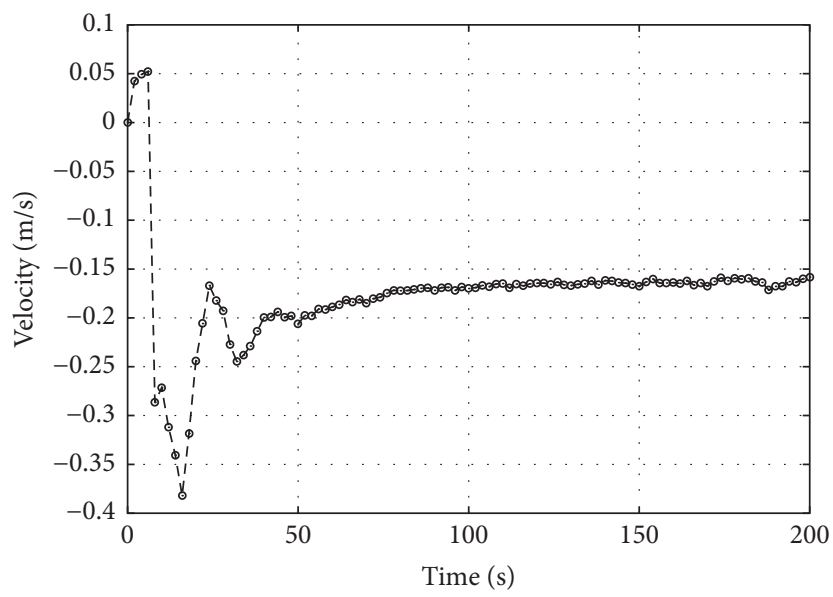

- - $V$ for $V_{i}=0.05 \mathrm{~m} / \mathrm{s}$

(a) Velocity

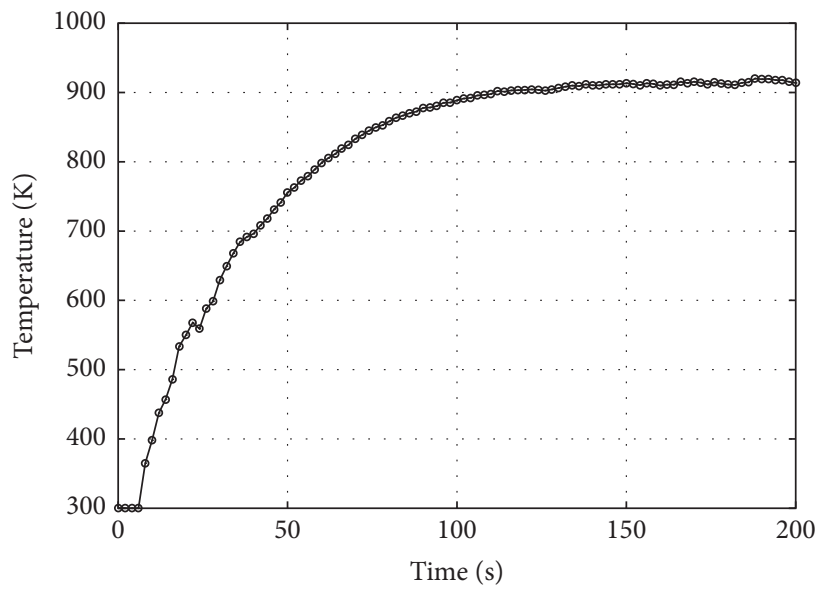

$\multimap T$ for $V_{i}=0.05 \mathrm{~m} / \mathrm{s}$

(b) Temperature

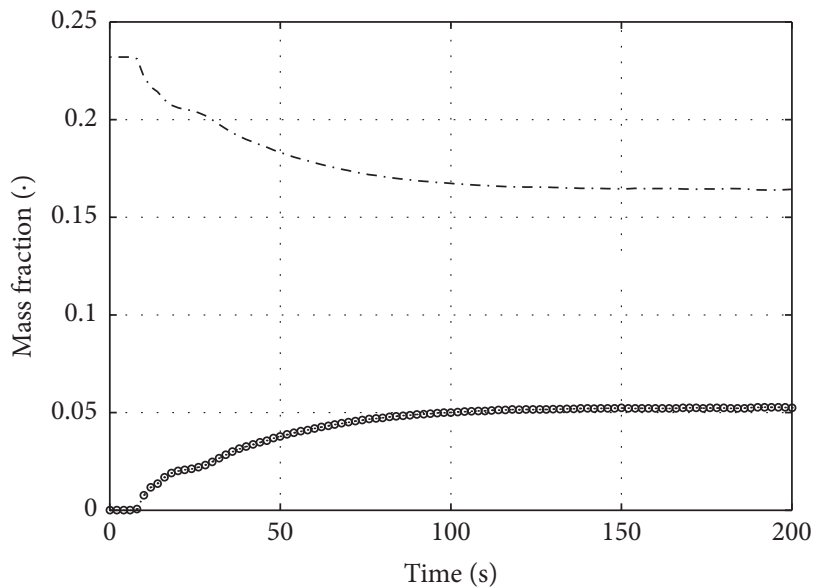

•... $\mathrm{CO}_{2}$ for $V_{i}=0.05 \mathrm{~m} / \mathrm{s}$

-. - $\mathrm{O}_{2}$ for $V_{i}=0.05 \mathrm{~m} / \mathrm{s}$

(c) Mass fraction

FIgURE 8: Upstream conditions for $V_{i}=0.05 \mathrm{~m} / \mathrm{s}$. 


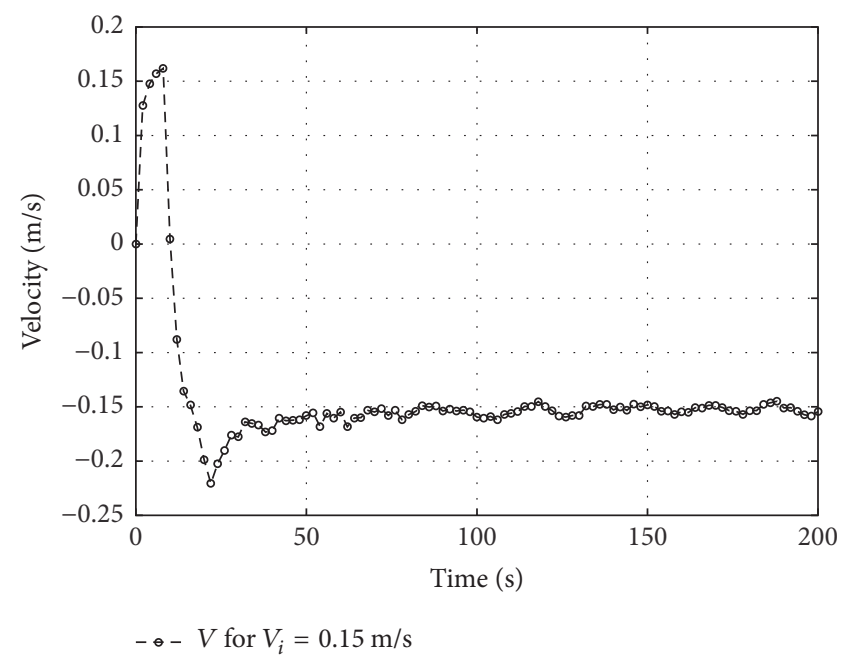

(a) Velocity

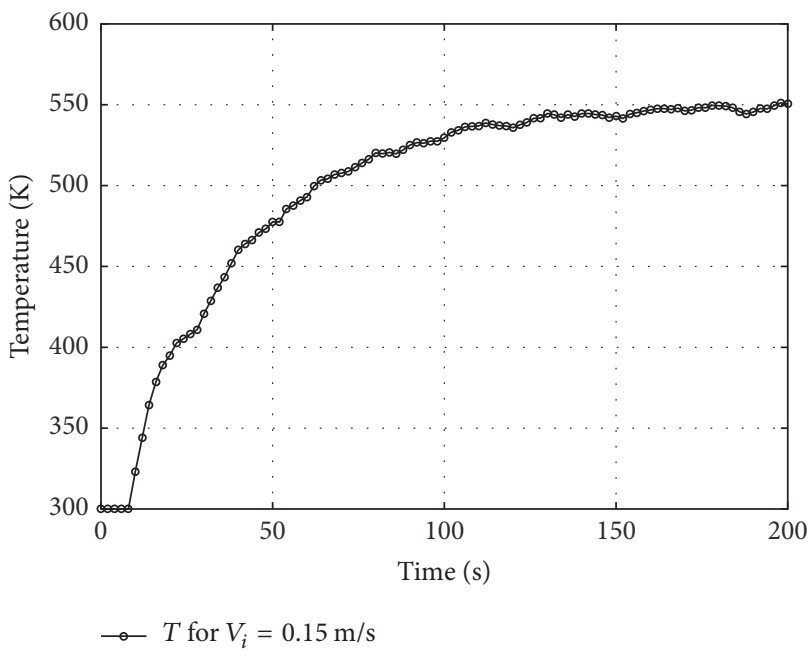

(b) Temperature

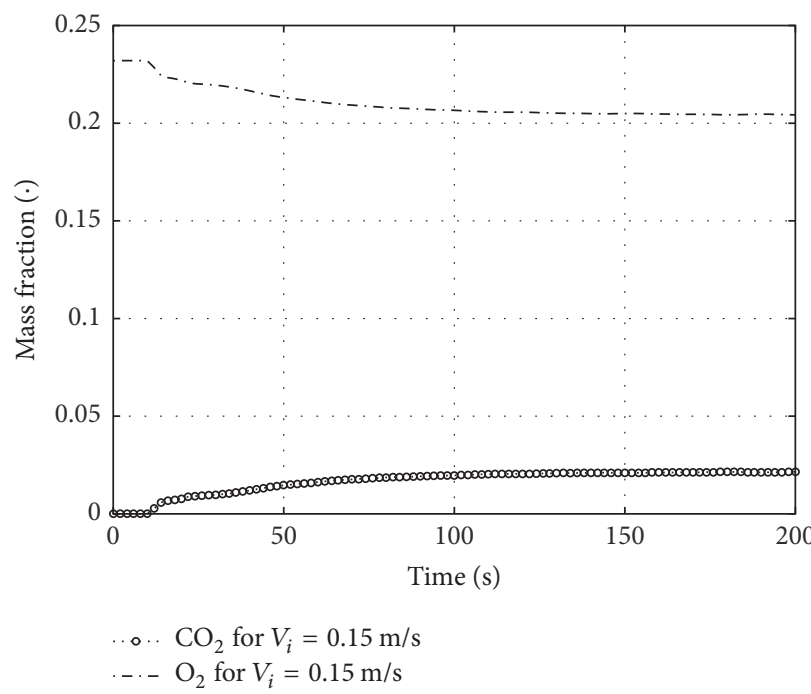

(c) Mass fraction

FIGURE 9: Upstream conditions for $V_{i}=0.15 \mathrm{~m} / \mathrm{s}$.

these conditions, the back layer always exists because of the negative value of velocity.

3.3.4. Velocity $V_{i}=0.32 \mathrm{~m} / \mathrm{s}$. Starting from ventilation velocity $V_{i}=0.32 \mathrm{~m} / \mathrm{s}$, some changes are observed. In fact, ventilation flow has positive effect in fire; it prevents the back-layer formation. When fire reaches its full developed stage, velocity level decreases considerably but stays above value zero (Figure 11(a)); that means that the velocity of reverse layer is zero, although temperature is around $370 \mathrm{~K}$ (Figure 11(b)) while the masses fractions are all normal (Figure 11(c)). So the ventilation velocity $V_{i}=0.32 \mathrm{~m} / \mathrm{s}$ fills the critical velocity's criteria.

3.3.5. Velocity $V_{i}>0.32 \mathrm{~m} / \mathrm{s}$. At these velocities, all the measured parameters are in normal values; by consequence, the tunnel upstream is free of smoke and combustion products while the tunnel downstream is full of flames, smoke, and hot and toxic gases (Figure 12).

Starting from this minimum velocity $\left(V_{i}=0.32 \mathrm{~m} / \mathrm{s}\right)$ setting velocity of the reverse layer to zero, whatever the velocity great than the latter, flow inside the upstream tunnel is stable; the ventilation system will always provide propitious conditions to allow firefighter's intervention and evacuation of eventual trapped people inside the tunnel and to avoid its destruction by flames.

3.3.6. Computation with Small HRR's Fuel. By repeating the computation progressively with the methanol as combustion's fuel, the ventilation's velocity sets the velocity of the layer to zero (Figure 13(a)) and temperature at this velocity is around 355 K (Figure 13(b)). 


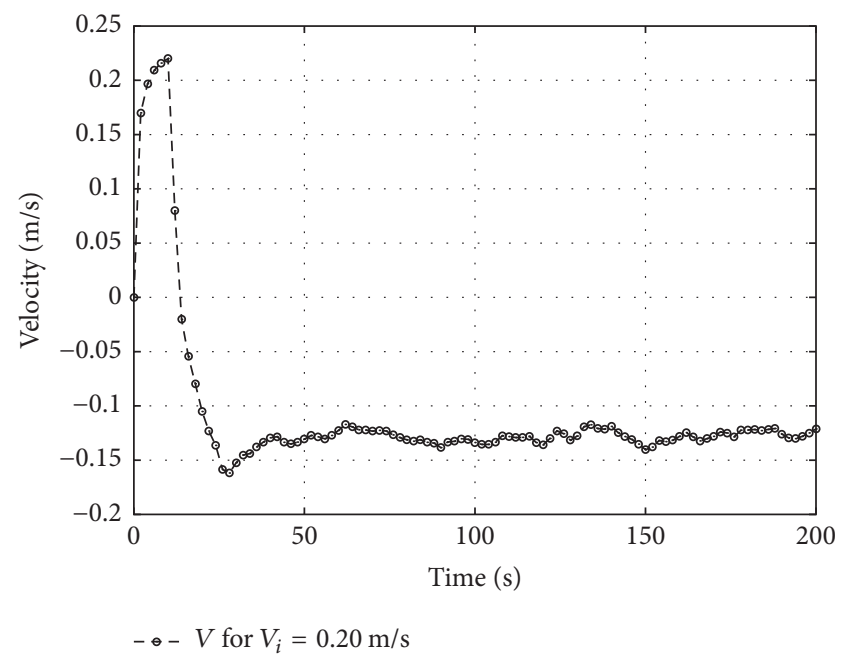

(a) Velocity

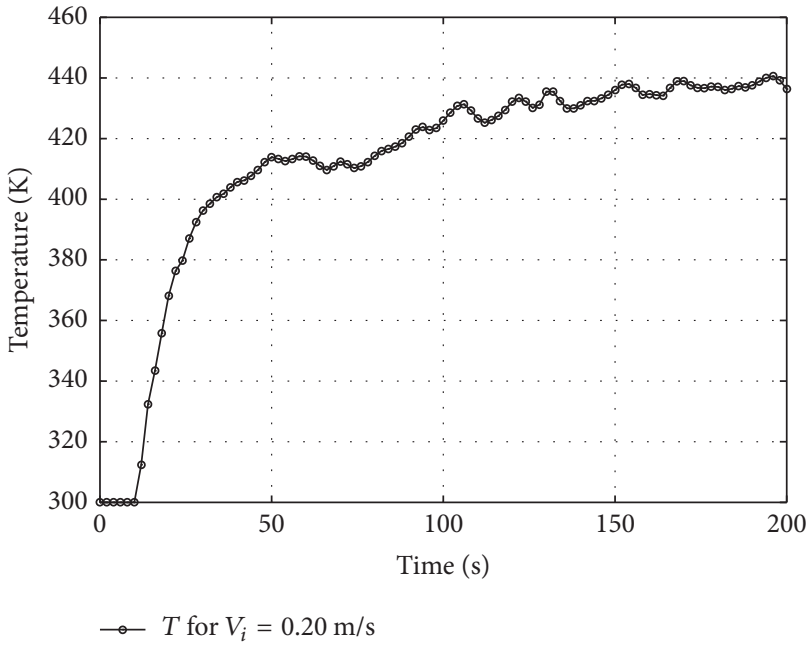

(b) Temperature

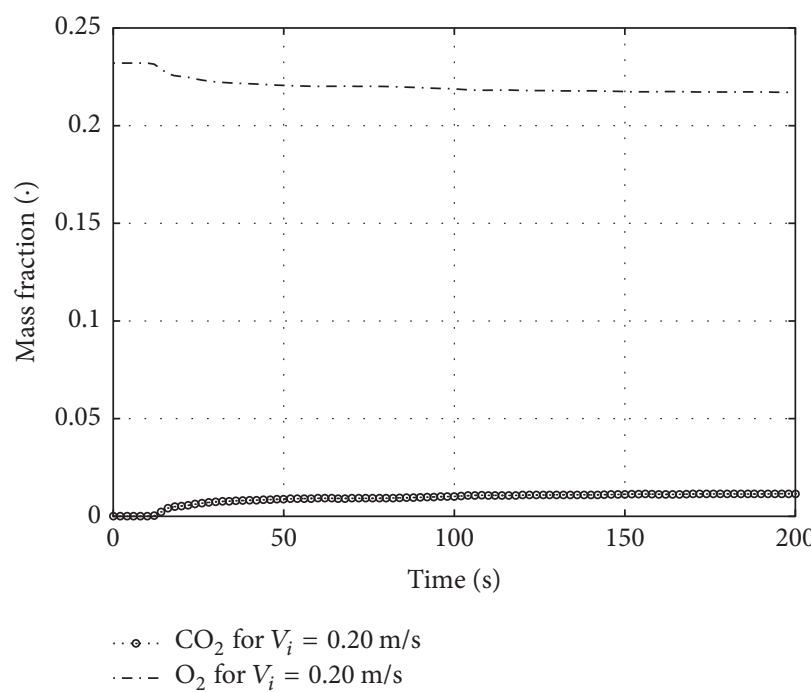

(c) Mass fraction

FIgURE 10: Upstream conditions for $V_{i}=0.20 \mathrm{~m} / \mathrm{s}$.

\section{Conclusion}

Tunnel fire situation is in principle different from the one where fire plume impinges on a ceiling, in which buoyancy force in the ceiling flow is function of ceiling height. In tunnel fire, buoyancy force in the back layer is due to the whole fire plume. Numerical study carried out in this work was in relation to tunnel fire, precisely its behavior over time depending of ventilation system operated. Intervention of firefighters in tunnel fire case often needs control of combustions gases and smoke, in order to reset visibility inside the upstream tunnel. In this numerical study, two computations with different HRR have been done and it came out that critical velocity is a function of thermic power released by the fire; so for simulation with HRR of $43.10^{3} \mathrm{~kJ} / \mathrm{kg}$, the minimum velocity is $1.12 \mathrm{~m} / \mathrm{s}$; as for $19.10^{3} \mathrm{~kJ} / \mathrm{kg}$, the minimum velocity is $1.34 \mathrm{~m} / \mathrm{s}$, both in full-scale conditions. So, ISIS is more useful for fire simulations in complex geometries as mine and road tunnels. In the next future work, it will be about the experimental work using the same small scale tunnel with the same conditions in order to validate actual numerical results.

\section{Competing Interests}

The authors declare that there is no conflict of interests regarding the publication of this paper.

\section{Acknowledgments}

The authors are grateful to the staff of IRSN, for the open access code and for the available online documentations. They would like to thank Mr. Babik Fabrice, Engineer Researcher at IRSN, for his kind support in ISIS code. 


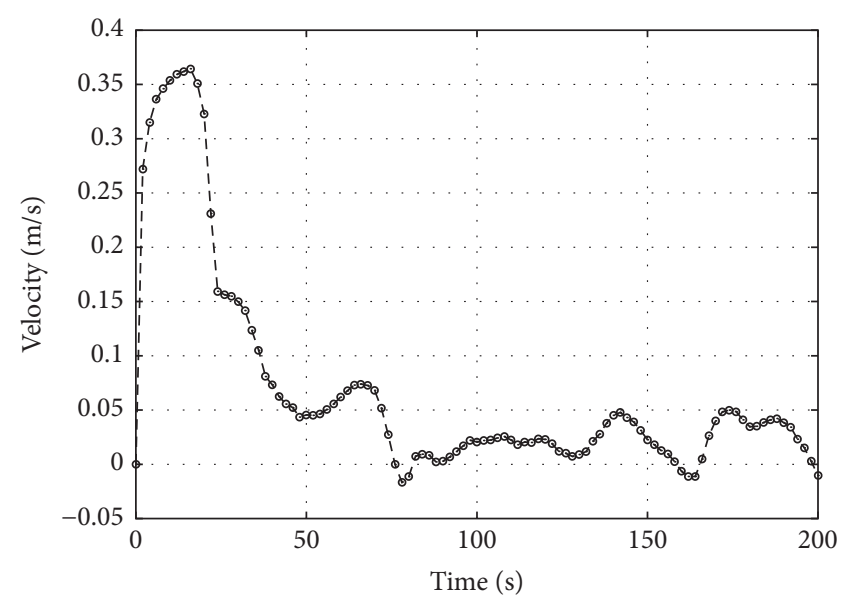

- $V$ for $V_{i}=0.32 \mathrm{~m} / \mathrm{s}$

(a) Velocity

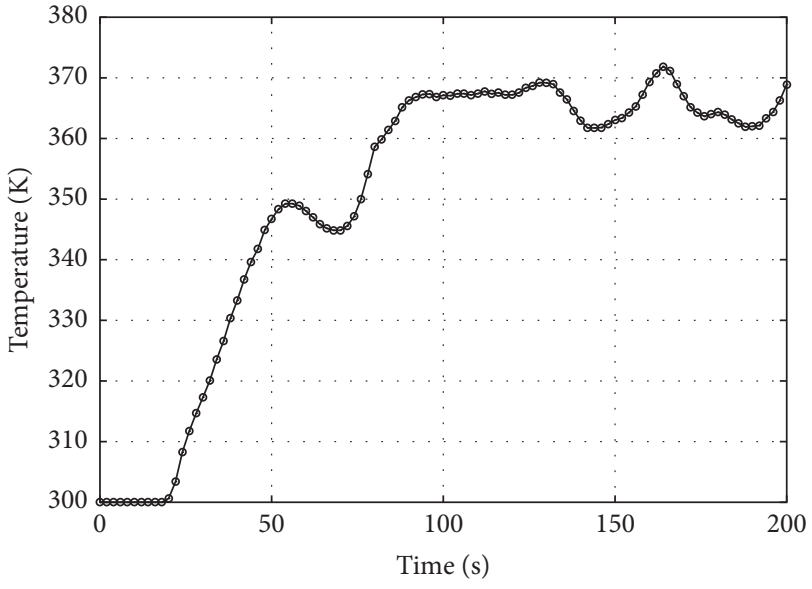

$\rightarrow T$ for $V_{i}=0.32 \mathrm{~m} / \mathrm{s}$

(b) Temperature

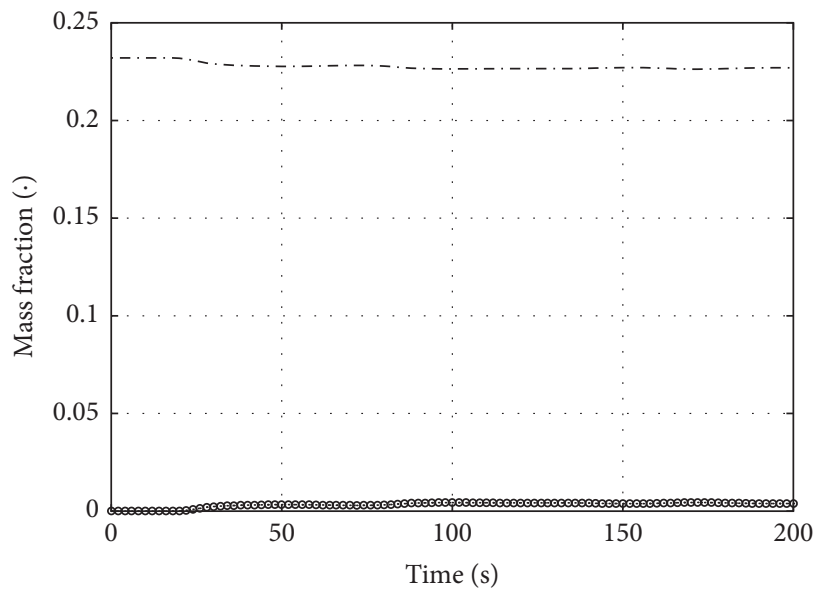

๑.. $\mathrm{CO}_{2}$ for $V_{i}=0.32 \mathrm{~m} / \mathrm{s}$

... $\mathrm{O}_{2}$ for $V_{i}=0.32 \mathrm{~m} / \mathrm{s}$

(c) Mass fraction

FIGURE 11: Upstream conditions for $V_{i}=0.32 \mathrm{~m} / \mathrm{s}$.

Upstream side free

of hot gases and smoke

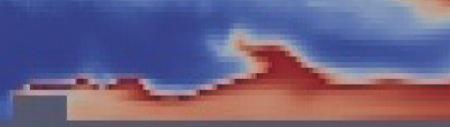

$T$

1200

1600

2000

|| || || || |||||||||||||||||||||||||||||||||||||||||||||||||||||||

300

2209.81

FIGURE 12: Visualization of upstream free of fire products at $V_{i}=0.38 \mathrm{~m}$. 


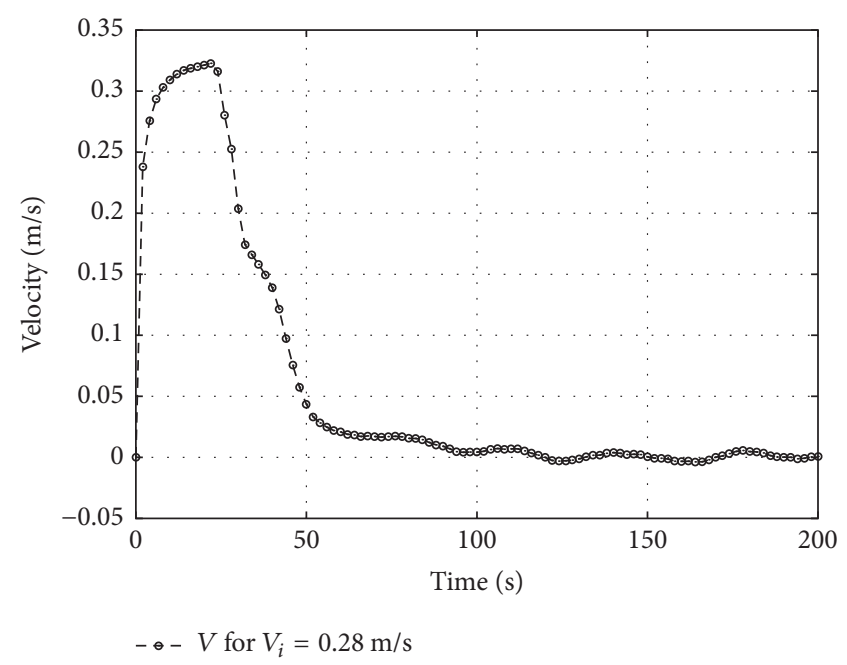

(a) Velocity

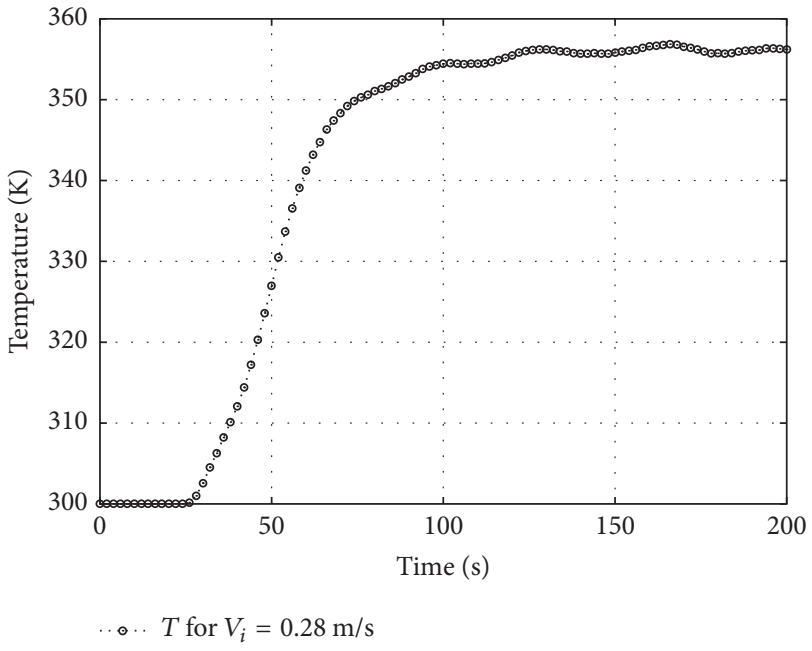

(b) Temperature

FIGURE 13: Upstream conditions for $V_{i}=0.28 \mathrm{~m} / \mathrm{s}$ with methanol as fuel.

\section{References}

[1] S. R. Lee, H. S. Ryou, and C. I. Kim, "An experimental study of smoke movement in tunnel fires with a vertical shaft," Korean Journal of Air Conditioning and Refrigeration Engineering, vol. 16, pp. 135-141, 2004.

[2] C. H. Cha and J. K. Kim, "Smoke control in subway tunnels," Korean Journal of Air-Conditioning and Refrigeration Engineering, vol. 28, pp. 425-432, 1999.

[3] O. Vauquelin, "Parametrical study of the back flow occurrence in case of a buoyant release into a rectangular channel," Experimental Thermal and Fluid Science, vol. 29, no. 6, pp. 725731, 2005.

[4] O. Vauquelin and Y. Wu, "Influence of tunnel width on longitudinal smoke control," Fire Safety Journal, vol. 41, no. 6, pp. 420426, 2006.

[5] L. H. Hu, R. Huo, H. B. Wang, Y. Z. Li, and R. X. Yang, "Experimental studies on fire-induced buoyant smoke temperature distribution along tunnel ceiling," Building and Environment, vol. 42, no. 11, pp. 3905-3915, 2007.

[6] L. H. Hu, R. Huo, and W. K. Chow, "Studies on buoyancy-driven back-layering flow in tunnel fires," Experimental Thermal and Fluid Science, vol. 32, no. 8, pp. 1468-1483, 2008.

[7] A. Lönnermark and H. Ingason, "Fire spread and flame length in large-scale tunnel fires," Fire Technology, vol. 42, no. 4, pp. 283-302, 2006.

[8] K. Brahim, B. Mourad, E. C. Afif, and B. Ali, "Study of the temperature distribution in a road tunnel under the effect of two ventilation systems," Journal of Environmental Protection, vol. 2, no. 3, pp. 231-242, 2011.

[9] Y. Wu and M. Z. A. Bakar, "Control of smoke flow in tunnel fires using longitudinal ventilation systems-a study of the critical velocity," Fire Safety Journal, vol. 35, no. 4, pp. 363-390, 2000.

[10] S. R. Lee and H. S. Ryou, "An experimental study of the effect of the aspect ratio on the critical velocity in longitudinal ventilation tunnel fires," Journal of Fire Sciences, vol. 23, no. 2, pp. 119-138, 2005.
[11] K. Brahim, B. Mourad, E. C. Afif, and B. Ali, "Control of smoke flow in a tunnel," Journal of Applied Fluid Mechanics, vol. 6, no. 1, pp. 49-60, 2013.

[12] D. F. Fletcher, J. H. Kent, V. B. Apte, and A. R. Green, "Numerical simulations of smoke movement from a pool fire in a ventilated tunnel," Fire Safety Journal, vol. 23, no. 3, pp. 305-325, 1994.

[13] J. Modic, "Fire simulation in road tunnels," Tunnelling and Underground Space Technology, vol. 18, no. 5, pp. 525-530, 2003.

[14] G. Kagou, B. Kola, and R. Mouangue, "CFD studies of the propagation and extinction of flame in an under-ventilated and over-ventilated enclosure," Journal of Taibah University for Science, vol. 10, no. 3, pp. 393-402, 2016.

[15] A. Mbainguebem, R. Mouangue, and B. T. Bianzeube, "CFD studies of soot production in a coflow laminar diffusion flame under conditions of micro-gravity in fire safety," Journal of Taibah University for Science, 2017.

[16] D. Sahu, S. Kumar, S. Jain, and A. Gupta, "Full scale experimental and numerical studies on effect of ventilation in an enclosure diesel pool fire," Building Simulation, pp. 1-14, 2016.

[17] A. A. Ager, N. M. Vaillant, and M. A. Finney, "Integrating fire behavior models and geospatial analysis for wildland fire risk assessment and fuel management planning," Journal of Combustion, vol. 2011, Article ID 572452, 19 pages, 2011.

[18] M. A. Finney and S. S. McAllister, "A review of fire interactions and mass fires," Journal of Combustion, vol. 2011, Article ID 548328, 14 pages, 2011.

[19] N. Tilley, X. Deckers, and B. Merci, "CFD study of relation between ventilation velocity and smoke backlayering distance in large closed car parks," Fire Safety Journal, vol. 48, pp. 11-20, 2012.

[20] C. C. Hwang and J. C. Edwards, "The critical ventilation velocity in tunnel fires-a computer simulation," Fire Safety Journal, vol. 40, no. 3, pp. 213-244, 2005.

[21] Institut de Radioprotection et de Sûreté Nucléaire-IRSN (20042013)/documentations, Available in the ISIS Collaborative website, April 2014.

[22] Y. F. Li and W. K. Chow, "Computational fluid dynamics simulation of fire-induced air flow in a large space building: key 
points to note," in Proceedings of the ASME Heat Transfer/Fluids Engineering Summer Conference, HT/FED, pp. 1163-1169, Charlotte, NC, USA, July 2004.

[23] W. Zhang, A. Hamer, M. Klassen, D. Carpenter, and R. Roby, "Turbulence statistics in a fire room model by large eddy simulation," Fire Safety Journal, vol. 37, no. 8, pp. 721-752, 2002.

[24] B. J. McCaffrey and J. G. Quintiere, "Buoyancy driven countercurrent flows generated by a fire source," in Heat Transfer and Turbulent Buoyant Convection, D. B. Spalding and N. Afgan, Eds., pp. 457-472, Hemisphere Publishing, Washington, DC, USA, 1977.

[25] H. Pretrel, P. Querre, and M. Forestier, "Experimental study of burning rate behaviour in confined and ventilated fire compartments," in Proceedings of the 8th International Symposium on Fire Safety Science, pp. 1217-1228, Beijing, China, September 2005.

[26] J. S. Roh, S. S. Yang, and H. S. Ryou, “Tunnel fires: experiments on critical velocity and burning rate in pool fire during longitudinal ventilation," Journal of Fire Sciences, vol. 25, no. 2, pp. 161-176, 2007. 


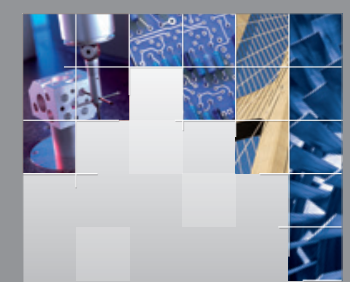

\section{Enfincering}
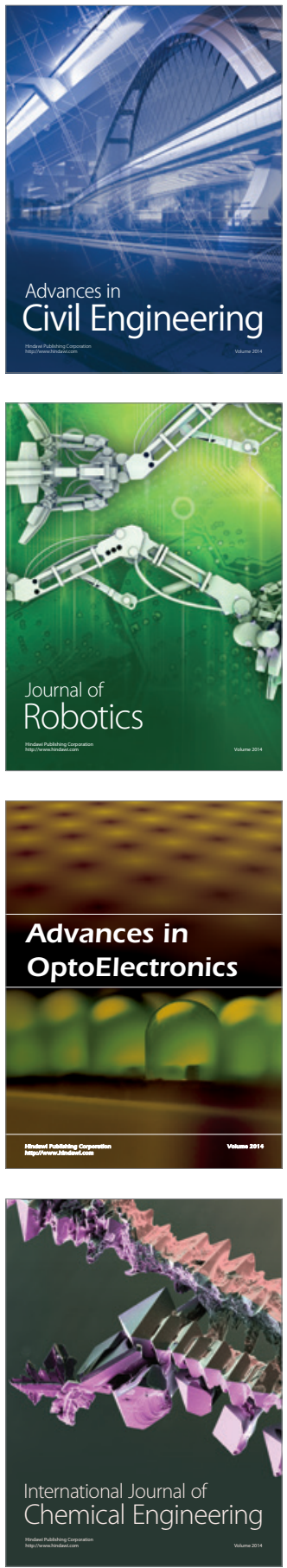

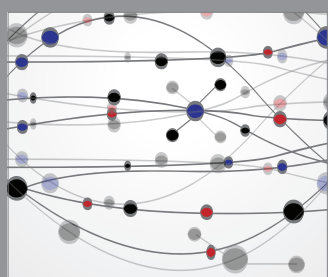

The Scientific World Journal

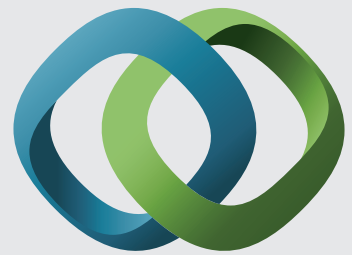

\section{Hindawi}

Submit your manuscripts at

https://www.hindawi.com
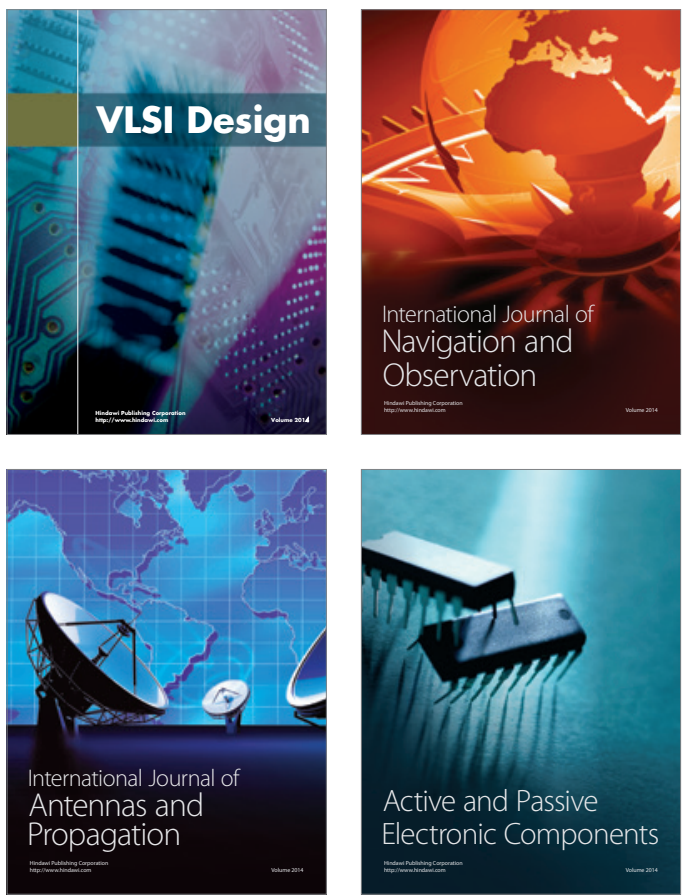
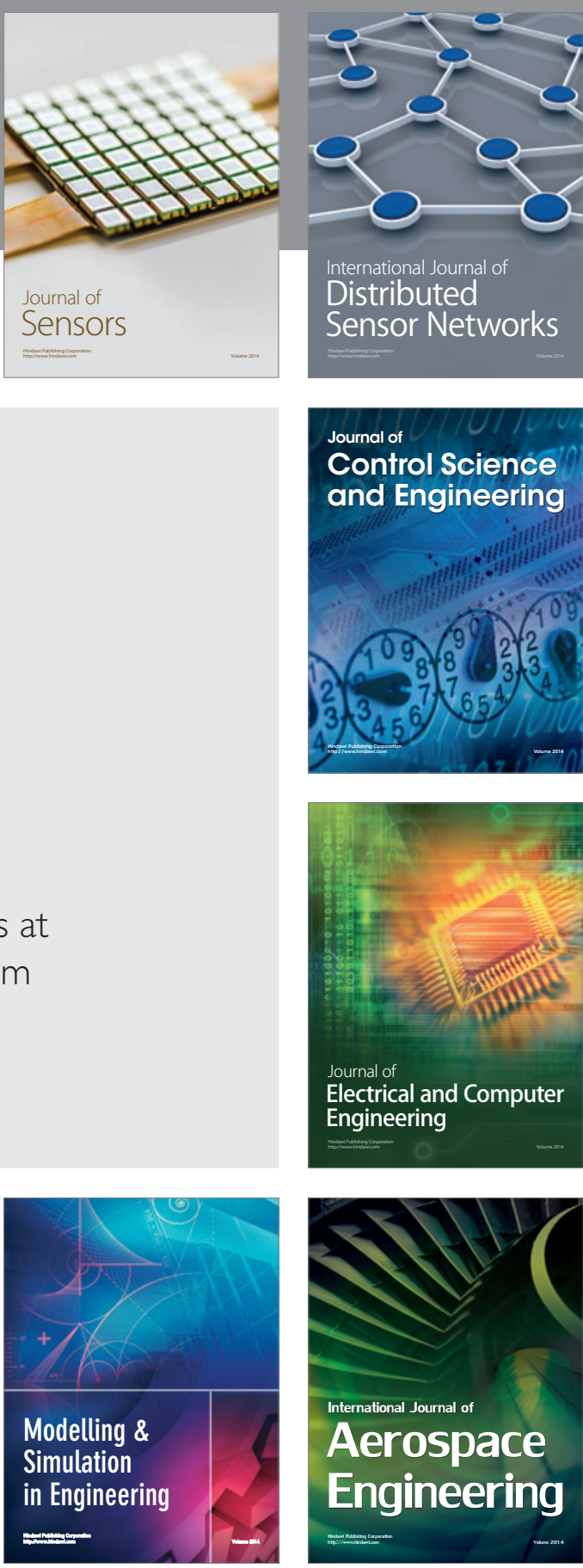

International Journal of

Distributed

Sensor Networks

$-$

Joumal of

Control Science

and Engineering
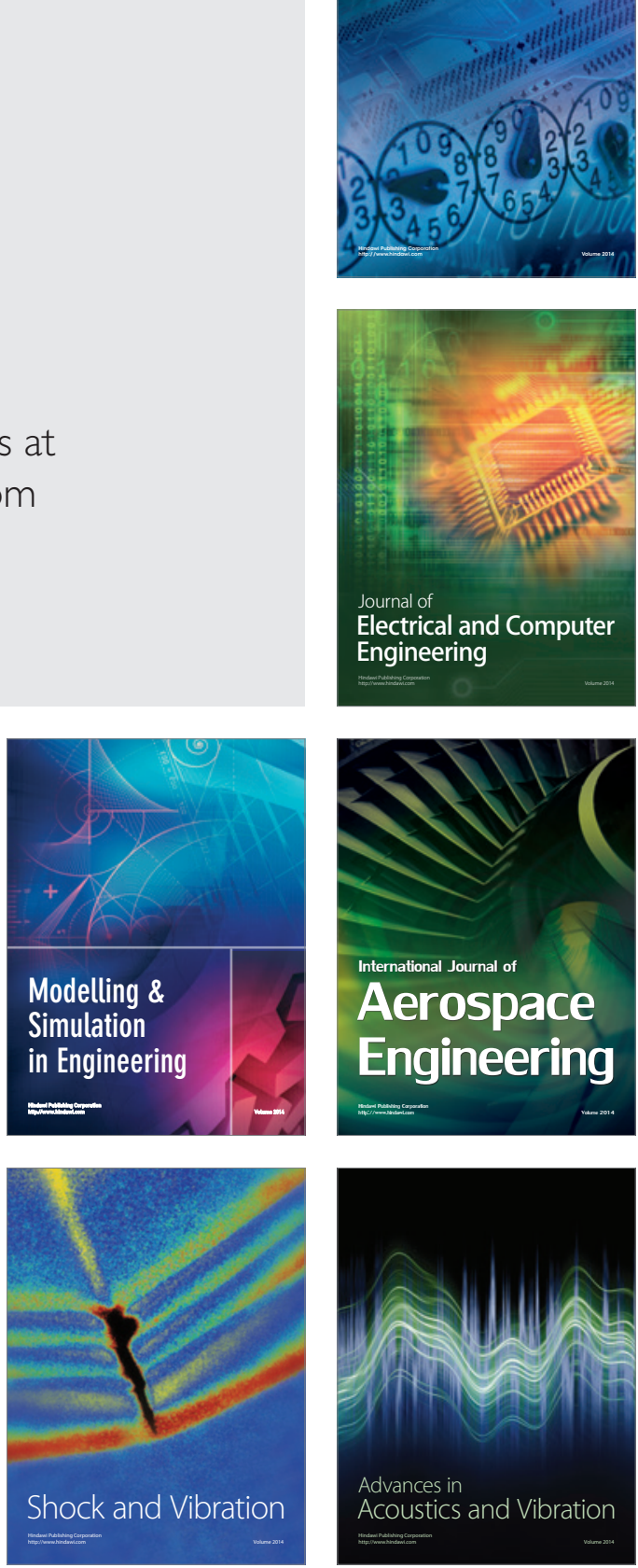